\title{
THE INFLUENCE OF AN ARCHITECTURAL DESIGN ALTERNATIVE TRANSOMS ) ON INDOOR AIR ENVIONMENT IN CONVENTIONAL KITCHENS IN TAIWAN
}

\author{
Che-Ming Chiang, Chi-Ming Lai, Po-Cheng Chou, Yen-Yi. Li
}

Department of Architecture, National Cheng-Kung University, Tainan, Taiwan, R.O.C.

\begin{abstract}
This study investigates indoor air environment via the flow fields, temperature fields and air contaminants (carbon monoxide) distributions in conventional residential kitchens, and looks for effective methods to solve those problems through natural ventilation techniques. Numerical simulations of the physical problem under consideration have been performed via a finite volume method for solving the governing equations and boundary conditions. It is obvious that location of accumulation of air contaminants is highly relevant to the location of gas fires, and realizing the dominant flow pattern will be successful in eliminating air contaminants. An architectural design aternative, utilizing transoms, is then proposed to improve indoor air environment in kitchens.
\end{abstract}

\section{INTRODUCTION}

Indoor air quality in Taiwan is poor due to crowded living spaces, highly airtight buildings, poor air circulation, and a lack of ventilation. This problem has been receiving more and more attention. Furthermore, a large fraction of typical indoor pollutants (oil-aerosol, water vapor, carbon monoxide, nitrogen oxides, and VOCs) are released, owing to conventional cooking behavior in Taiwan, e.g. decocting, frying, boiling, scrambling...etc. Chiang et al (1996) performed in-situ field measurements of the impact of outdoor air, and living behavior patterns, on indoor air quality of apartments in Taiwan 【1】. It appears that the highest average concentration of carbon monoxide in residential kitchens occurred during the cooking period when there was a large variation shown in the indoor concentration ( 24-hour average), ranging from 0.1 to $13.9 \mathrm{ppm}$. In $25 \%$ of the cases, the indoor hourly concentration exceeded 9 ppm, ASHRAE criteria. According to statistics issued by Taiwan's Department of Health, lung cancers figure highly among women's diseases in Taiwan. It is suspected that a strong relationship exists between lung cancers and indoor air quality in kitchens, due to the existence of oil-aerosol and gaseous contaminants.

Recently, further efforts on the natural ventilation system have been made, due to the environmental benefits and energy saving aspects for residential buildings 【2-4】. It is important to perform the ventilation of the space efficiently in consideration of health and thermal comfort. The objective of the present study is to provide physical insight into the nature of buoyancy-driven air flow and natural ventilation phenomena in conventional kitchens in Taiwan, for which little or no information is available. In so doing, numerical simulations via a finite volume method have been performed for the steady three-dimensional turbulent flow phenomena induced by a heat source (gas fire). Complementary to the numerical simulations, full-scale experiments were also conducted for the physical configuration under consideration. Of particular emphasis in this study were the window-transom proposals designed to attain an improved indoor air environment in those 


\section{METHOD}

\section{( 1 ) Model Kitchen}

In Taiwan, many houses are built by the government, and then sold to citizens. Usually we call them " public houses ". In the processes of planning, designing, constructing, and maintaining, economic moduli and threshold limits of necessities for living are taken into consideration. To a great extent, they are referred to as " conventional buildings ". Ho et al (1993) surveyed almost all the public houses in Taiwan, and got conclusive information about furniture types/layouts and conve ntional length scales as they appeared in those public houses

【5】. In accordance with those research results, main length scales and relevant parameters for a model kitchen are decided. It is depicted schematically in Fig. 1. The geometric data of this model house is listed in Table 1.

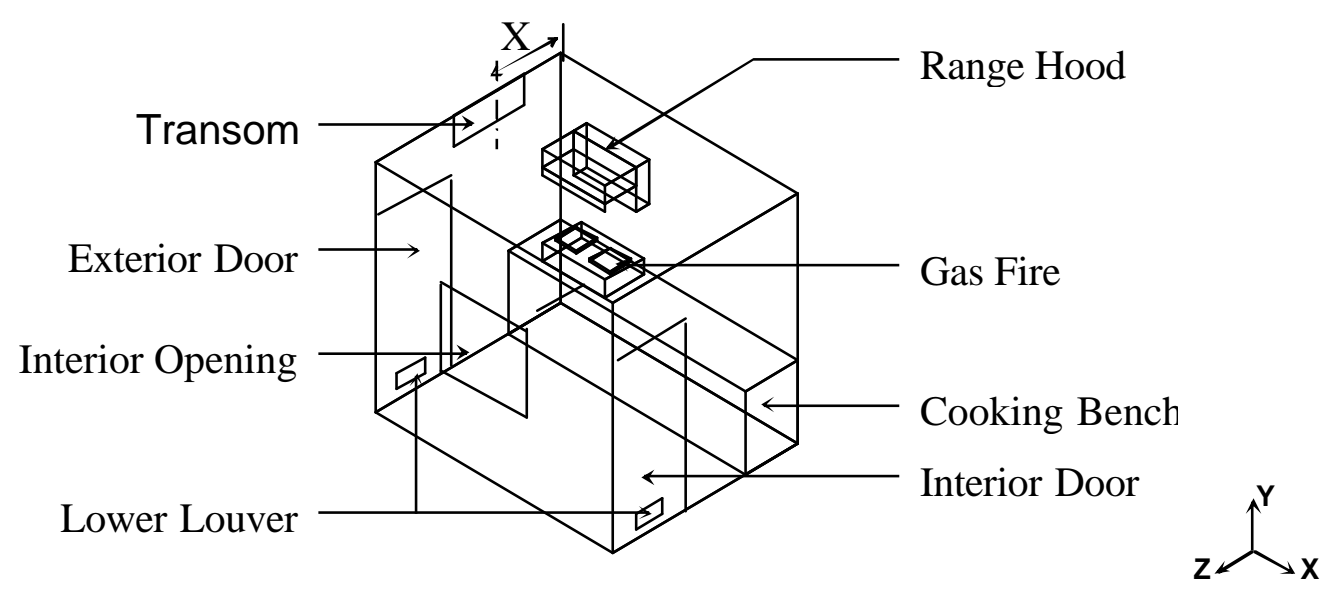

Fig. 1 Schematic diagram of the model kitchen investigated

Table 1 Geometric data of the model kitchen ( unit : $\mathrm{cm}$ )

\begin{tabular}{c|c}
\hline \hline Model kitchen & $270 \times 210 \times 240$ \\
\hline Cooking bench & $270 \times 53 \times 80$ \\
\hline Gas fire & $70 \times 43 \times 21.2$ \\
\hline Range hood & $89 \times 57.6 \times 42$ \\
\hline Interior opening & $90 \times 120$ (elevation:90) \\
\hline Transom & $30 \times 80$ (elevation:210) \\
\hline Location of the transom, $\mathrm{X}$ & $40,80,120,160$ \\
\hline \hline
\end{tabular}

\section{( 2 ) Physical Problem}

Fig. 1 illustrates schematically the physical configuration of the air environment which is undergoing ventilation processes through a transom opening (natural ventilation) in conventional residential kitchens in Taiwan. Initially air is at its domestic temperature $T_{i}$ in Taiwan. Suddenly, the heat flux generated by the gas fire raises the temperature of air adjacent to this region. The buoyancy-driven airflow resulting from the temperature difference between the gas fire and ambient air is assumed to be three-dimensional and turbulent. Furthermore, the thermophysical properties of the air are temperature independent, except for the density, for which the Boussinesq approximation is valid. The other dimensional parameters specified 
in this study are shown in Table 2 .

Table 2 dimensional parameters specified in numerical calculation

\begin{tabular}{l|l}
\hline \hline Initial temperature $\mathrm{T}_{\mathrm{i}}$ & $\begin{array}{l}26^{\circ} \mathrm{C}(\text { statistically average temp. in summer } \\
\text { in Taiwan })\end{array}$ \\
\hline Wall of the kitchen & Adiabatic \\
\hline Heat flux generated by the gas fire & $5.9 \times 10^{5}\left(\mathrm{w} / \mathrm{m}^{2}\right)$ \\
\hline Carbon monoxide produced by combustion & $1.1 \times 10^{-3}\left(\mathrm{~kg} / \mathrm{m}^{2} \mathrm{~s}\right)$ \\
\hline Outdoor carbon monoxide concentration & $3 \mathrm{ppm}$ \\
\hline Suction flow rate of the range hood & $14.5 \mathrm{~m}^{3} / \mathrm{hr}$ \\
\hline \hline
\end{tabular}

\section{( 3 ) Numerical Method}

Numerical simulations of the physical problem under consideration have been performed via a finite volume method for solving the governing equations and boundary conditions mentioned above. This study applies the SIMPLE ( Semi-Implicit Method for Pressure Linked Equations ) algorithm 【6】 to solve those equations. The " two equation model " of turbulence, the k-epsilon model, 【7】 was adopted. To bridge the steep dependent variable gradients close to the solid surface, the " general wall function " is employed. The iteration calculation was continued until a prescribed relative convergence of $10^{-4}$ was satisfied for all field variables of this problem. A $38 \times 28$ x 32 grid system was employed for the present calculations.

\section{( 4 ) Full Scale Experiment}

In order to investigate the indoor air environment in the kitchen, experiments were also performed in a full-scale model kitchen(built in National Cheng Kung University) that perfectly matches the physical configuration depicted in Fig. 1. The characteristics of the air velocity field are measured by a three-dimensional ultrasonic anemometer. The accuracy of the ultrasonic anemometer is $\pm 2 \%$ within full scale (within the range of the main air velocity direction after zero-point adjustment). The temperature field is measured by T-type thermocouples and recorded in the data log. The uncertainty of temperature measurement is less than $2 \%$.

\section{NUMERICAL RESULTS}

Numerical simulations have been undertaken for the steady-state, three dimensional turbulent flow in six conventional kitchens, with the following parameter configurations listed in Table 3. The numerical results will therefore be presented with a primary focus on the influence of those configurations on the airflow patterns, temperature fields and carbon monoxide distributions in those kitchens.

Table 3 Configurations for numerical simulation (N.O. means not opened/operating)

\begin{tabular}{l|c|c|c|c|c}
\hline \hline Features & Range hood & Interior door & Exterior door & Interior opening & transom \\
\hline (1 ) Dominant flow pattern & N.O. & Closed, but the lower louvers & OPEN & N.O. \\
\cline { 5 - 6 } ( 2 ) Effect of architectural alternative--transom & N.O. & are still opened. & N.O. & Opened \\
\hline \hline
\end{tabular}




\section{( 1 ) Dominant flow pattern}

The numerical results will therefore be presented with a primary focus on the influence of the gas fire's location ( left, middle, and right-hand side of the bench ) on turbulent flow patterns and temperature/carbon dioxide distribution in the conventional kitchens, as illustrated in figure 2. When the gas fire is located on one side of the bench, air contaminants with high temperatures will accumulate at the corner of the upper space; when the gas fire is located on the middle, all the distributions are symmetric and the accumulations still exist beyond the gas fire. It is obvious that the location of the accumulation of air contaminants is highly relevant to the location of the gas fire. According to the flow patterns we discovered, we decide intuitively to "punch" a hole (transom) which can expel the convective thermal-plume to the outdoors directly. This is the context of those following cases where the removal efficiency of the transom is examined.
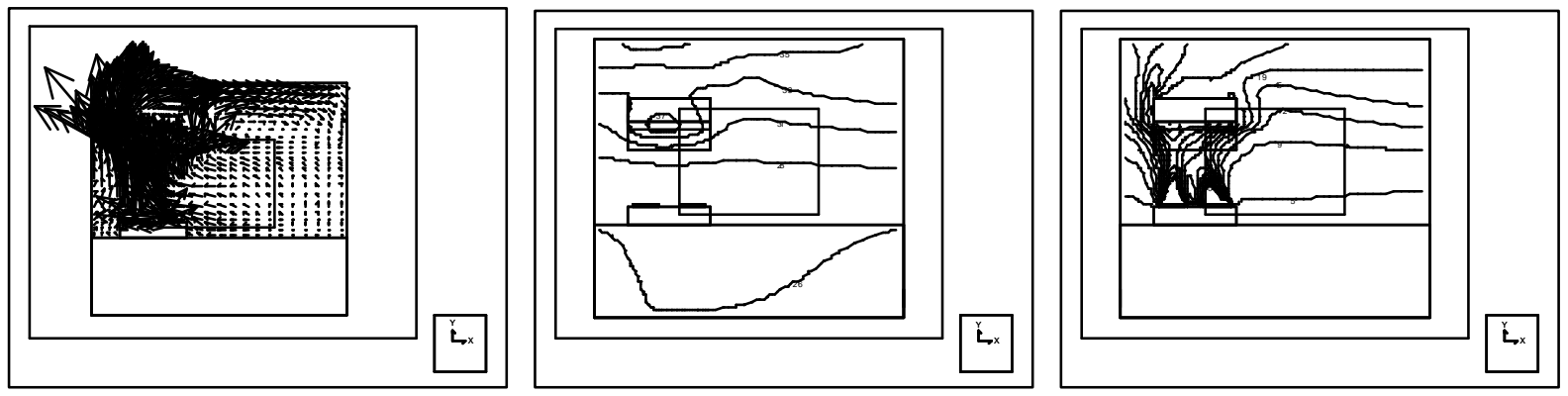

(a) The gas fire is located on the left-hand side of the bench
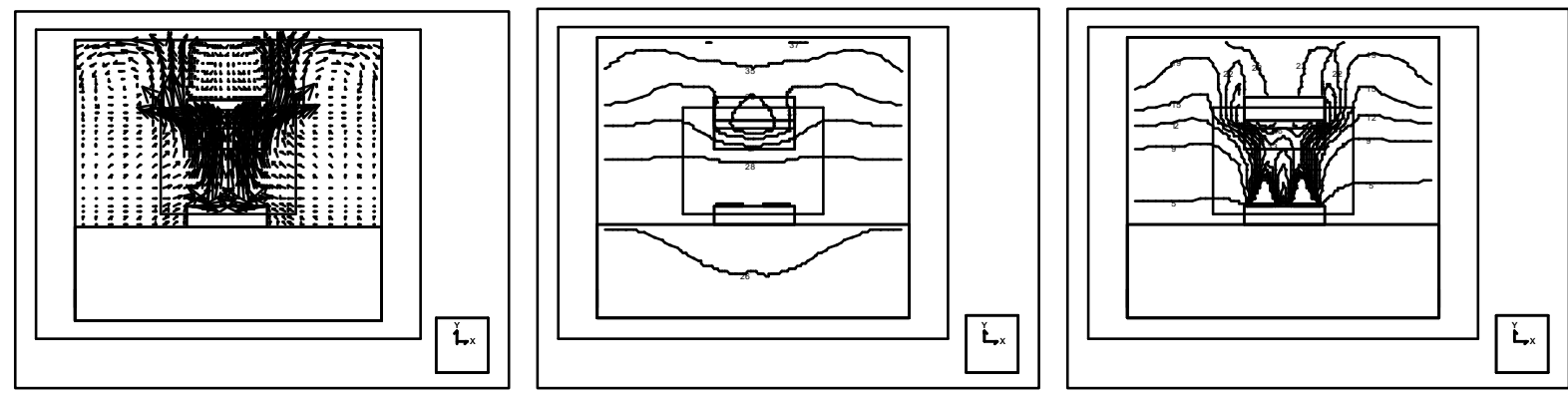

(b) The gas fire is located on the middle of the bench
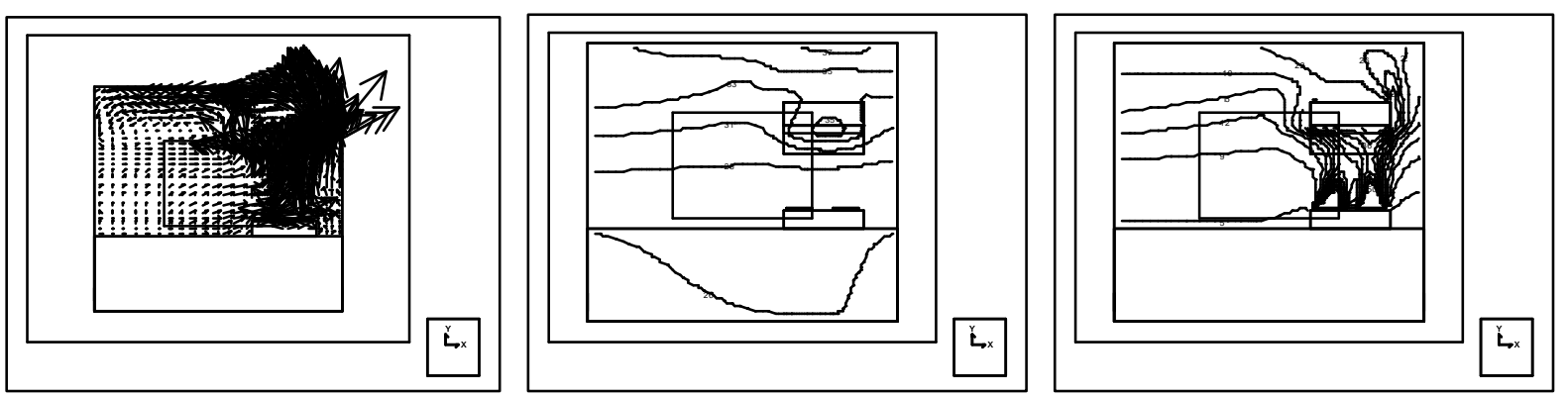

(c) The gas fire is located on the right-hand side of the bench

Fig. 2 Velocity vector diagram ( left ), temperature distribution ( middle ) and $\mathrm{CO}$ concentration profile ( right ) 


\section{( 2 ) Effect of the Architectural Alternative--transoms}

Figs. 3 to 5 exemplify the flow structures, temperature fields and carbon monoxide distributions in the model kitchens when the location of the transom, X, is $40 \mathrm{~cm}$. Fig. 6 shows that variation of temperature and carbon monoxide concentration in the model kitchens occurs when the transom is installed at different locations. It appears that the transom's performance in removing high temperature air with contaminants is excellent, especially when the location is properly arranged. We can realize that to attain an improvement of indoor environment not only depends on mechanical facilities, but proper architectural design-another economical way.

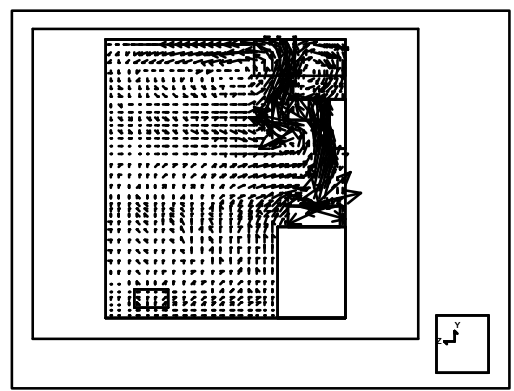

Fig. 3 Velocity vector diagram

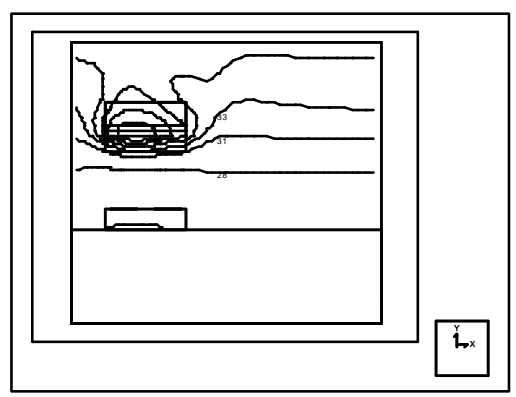

Fig. 4 Temperature field

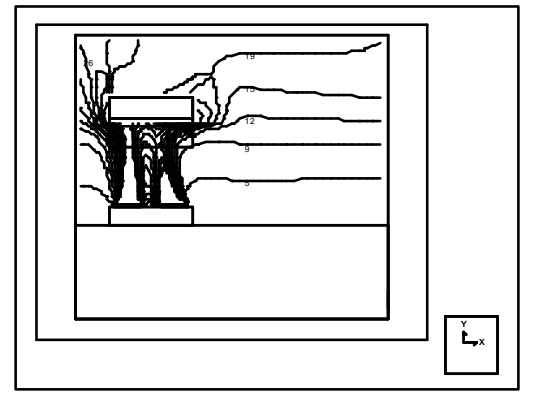

Fig. 5 CO distribution

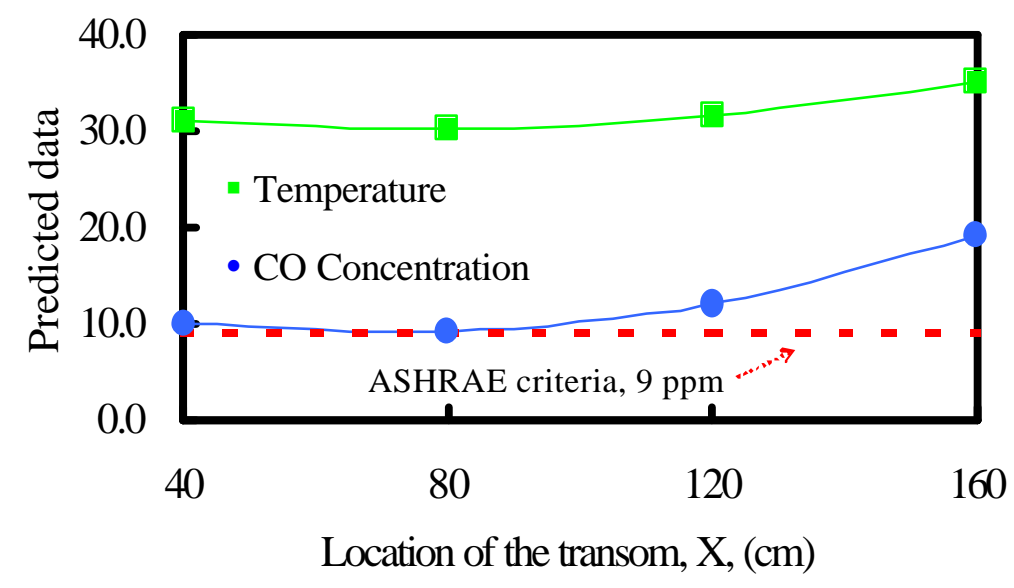

Fig. 6 variation of temperature and CO Concentration at different transom location, $\mathrm{X}$

\section{COMPARISON WITH FULL SCALE EXPERIMENTS}

Finally, it is necessary to validate the accuracy of the numerical simulations undertaken. Fig. 7 shows the computed temperature field with the measurements for an opened interior opening, constant air inward velocity from an exterior door $(0.3 \mathrm{~m} / \mathrm{s})$, constant inward air temperature $\left(26.4{ }^{\circ} \mathrm{C}\right.$ and $14.8^{\circ} \mathrm{C}$ ) and the operated range hood. A generally good qualitative agreement can readily be observed. 


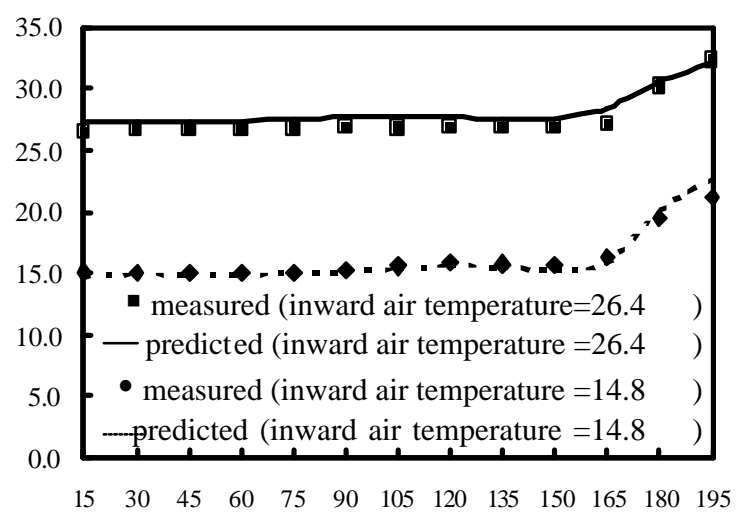

Fig. 7 Variation of temperature at the breathing zone with the distance to the interior opening

\section{DISCUSSION}

In the present article, the problem of improvement of indoor air environment in conventional residential kitchens in Taiwan has been studied numerically by means of finite volume method. Results from the numerical simulations undertaken indicate that:

1. The location of the accumulation of air contaminants is highly relevant to the location of the gas fire in conventional kitchen in Taiwan.

2.When the location of the transom is close to the region of accumulation of air contaminants, it's performance in removing air contaminants is excellent.

\section{ACKNOWLEDGEMENTS}

Support from the National Science Council of the ROC through grant No. NSC 88-2211-E-006-047 in this study is gratefully acknowledged. Also, we are especially grateful to ARCHILIFE Research Foundation for their computational facilities.

\section{REFERENCES}

1.Chiang, C. M., Chou, P. C. et al.1996. A study of the impacts of outdoor air and living behavior patterns on indoor air quality - case studies of apartments in Taiwan. INDOOR AIR' 96. 3:735-740.

2.Chiang, C. M., Chou, P. C. and Lai, C. M. et al. 1998. Numerical Simulation of Natural Ventilation of a Bedroom in Warm Climate. ROOMVENT '98.2:563-567.

3. Chung, K. C., Chiang, C. M. and Wang, W. A. 1997. Predicting Contaminant Particle Distributions to Evaluate the Environment of Lavatories with Floor Exhaust Ventilation. Building and Environment. 32(2):149-159.

4. Wang, W. A., Chou, P. C. and Chiang, C. M. 1997. Investigation on the Airflow Distribution in a Cross Ventilated Residential Bedroom. Healthy Building / IAQ' 97. 3:87-90.

5.Ho, U. F .et al. 1993. Development of the geometric guideline for civil houses. BRI, Department of the Interior, Taiwan. ( In Chinese. )

6.Patankar, S. V. 1980. Numerical Heat Transfer and Fluid Flow. Hemisphere. Washington.

7.Launder B. E. and Spalding, D. B. 1974. Computer Methods in Applied Mechanics and Engineering.

8. Chiang, C. M., Lai, C. M., Chou, P. C. and Li, Y. Y., 1998, Predicted Improvement of Indoor Air Environment in the Conventional Residential Kitchens in Taiwan, ICHES'98, Yokohama, JAPAN. 